\title{
Notes on the vocalizations of Common Chiffchaff (Phylloscopus collybita)
}

Peter Boesman

In the following we briefly analyze and compare voice of the different races of Common Chiffchaff (Phylloscopus collybita). We also try to quantify the extent of any vocal differences using the criteria proposed by Tobias et al. (2010), as a support for taxonomic review. We have made use of sound recordings available on-line from Xeno Canto (XC).

This is a well-known taxonomic case, a lot has already been written about it, but as often is the case much less so about voice.

A comparison of voice per race, illustrated with sonograms:

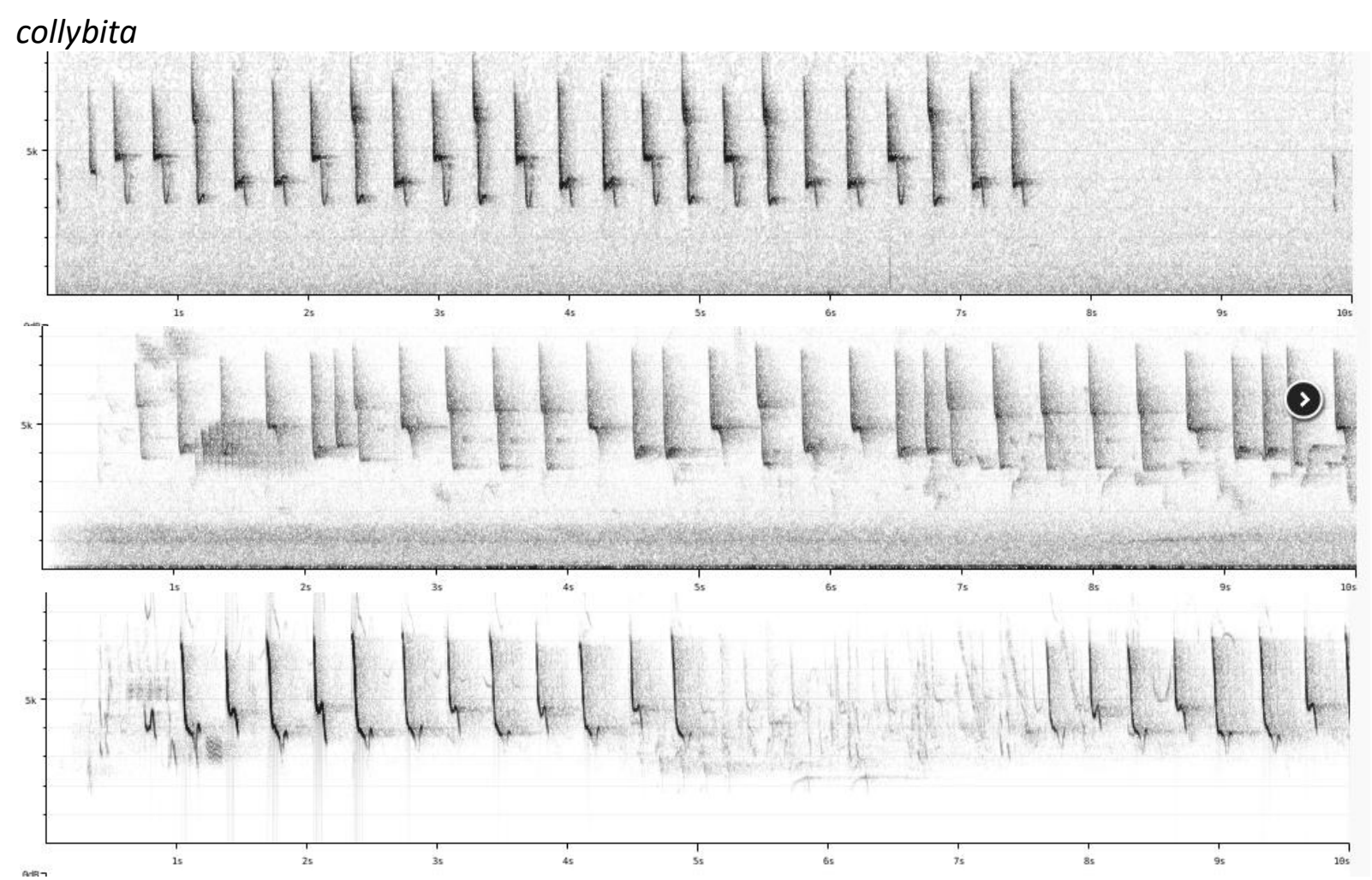

abietinus

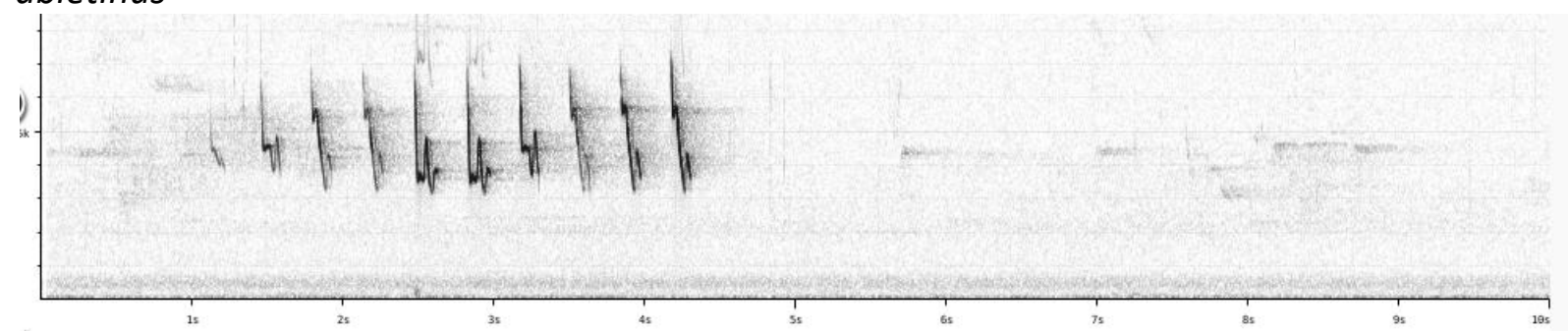



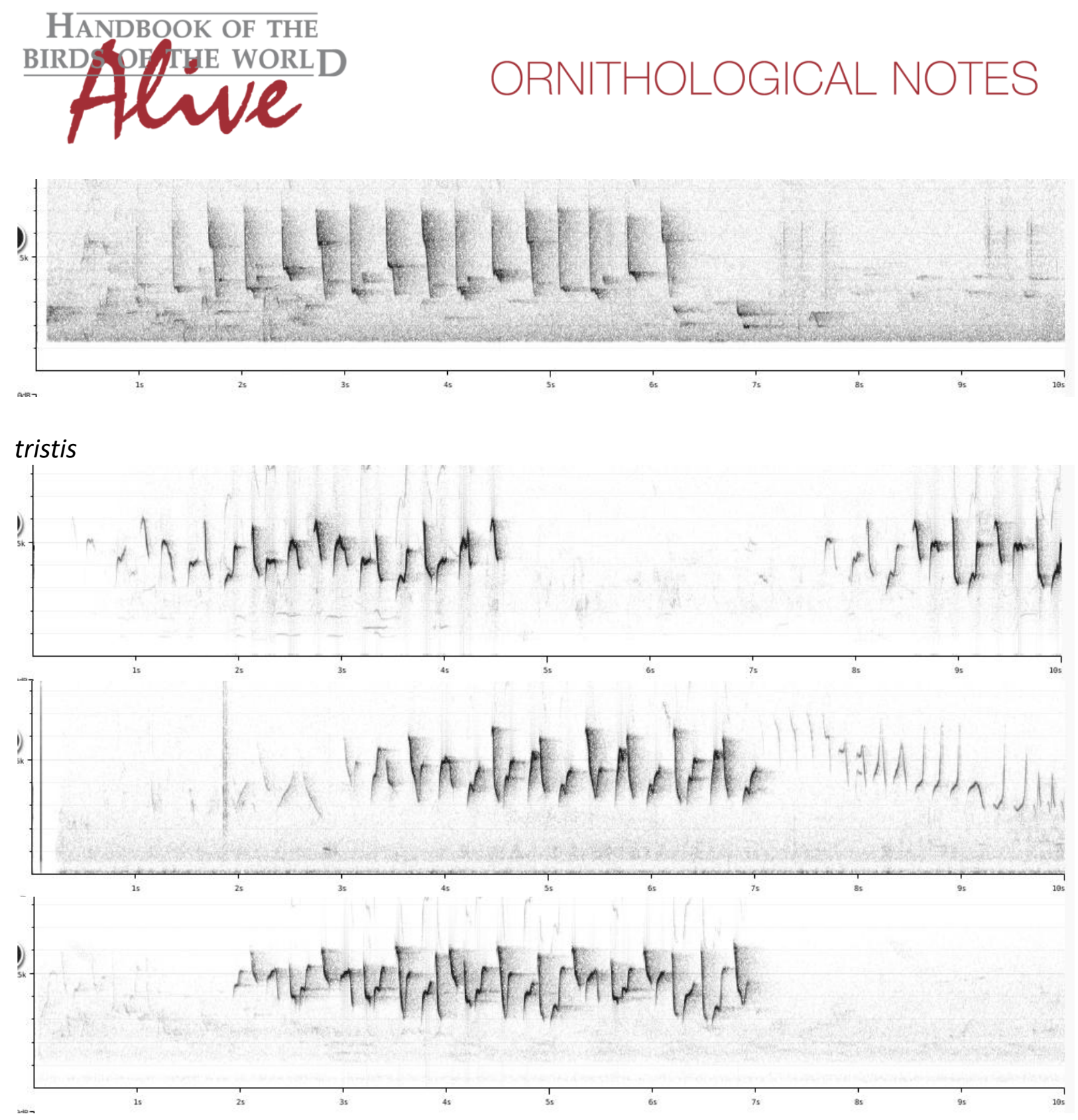

From the above examples it is quite clear that song of tristis is different: song of collybita (and abietinus) is a long series consisting of usually two repeated different short strident notes more or less alternating (hence its name Chiffchaff), song of tristis is much more melodious, typically a subphrase of 3-4 whistled notes repeated. Vocal difference of tristis can thus be quantified by faster pace (2-3), narrower frequency range of single notes (2-3), lower maximum frequency (2) and many more different note shapes including overslurred and rising notes (1-2) generally absent in collybita/abietinus.

Application of Tobias criteria would lead to a total vocal score of about 5.

Obviously, we make abstraction here of mixed songs, which are known from the presumed hybridization zone between tristis and abietinus. 

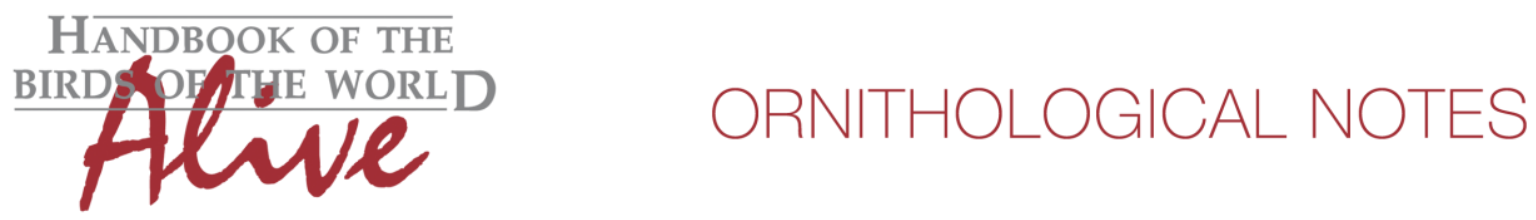

In the same way, the most common call type is quite different:

collybita

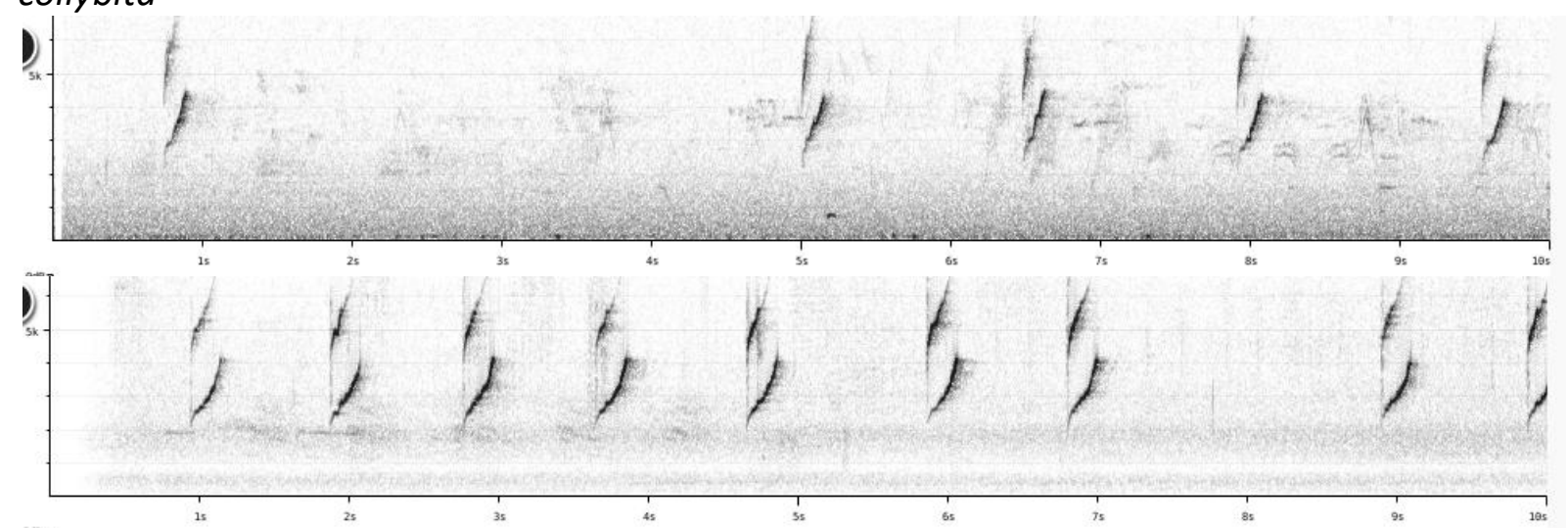

abietinus

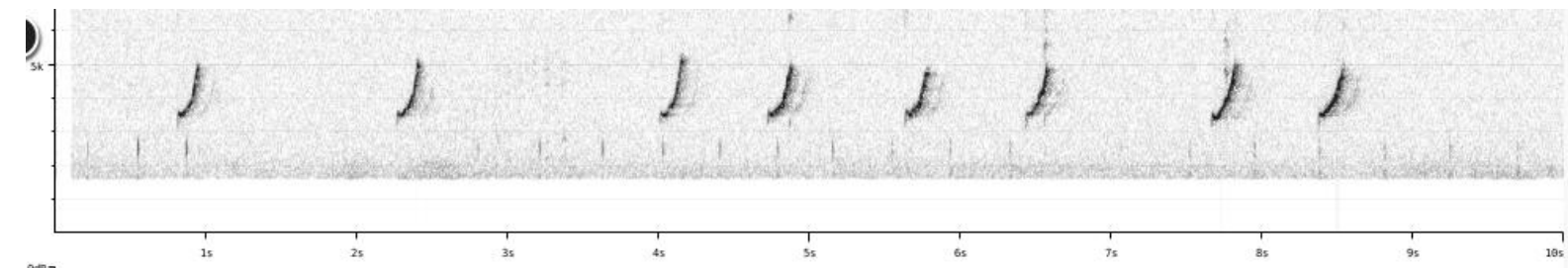

tristis

)

).

Commonest call of collybita and abietinus is a mellow rising "hweet!", while call of tristis is a short somewhat piping "peew".

The Caucasian races are much less well documented, and recordings from that region are complicated by the presence of migrant birds in spring. Song seems however to be 'Chiffchaff-like':

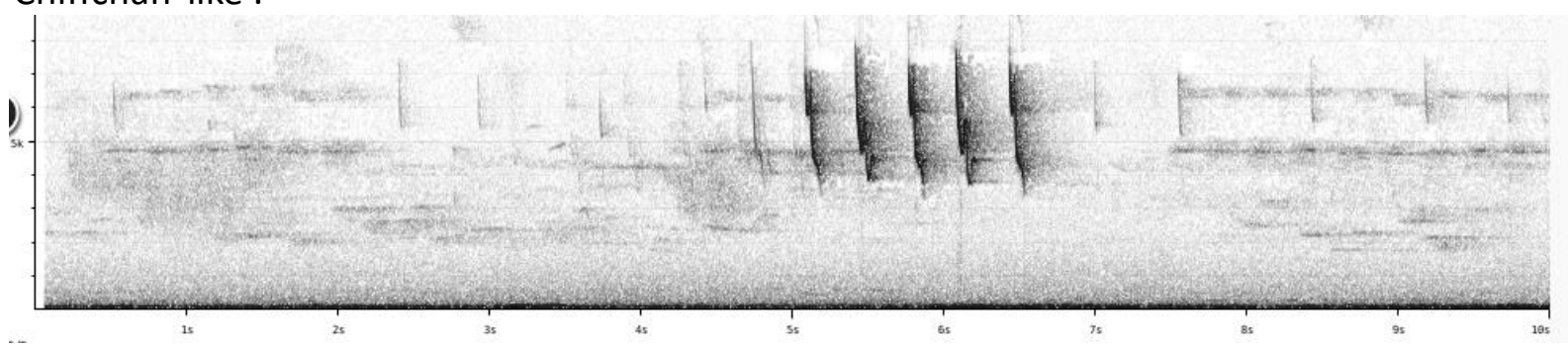

Other issues that need further research are the calls of wintering birds in Cyprus, Turkey and the Middle-East. Many calls are 'tristis'-like, but true racial identity needs confirmation.

While it is clear that further research is still needed, it is equally clear that there is a significant vocal difference between tristis and collybita/abietinus. 
This note was finalized on 24th February 2016, using sound recordings available on-line at that moment. We would like to thank in particular the many sound recordists who placed their recordings for this species on XC.

\section{References}

Tobias, J.A., Seddon, N., Spottiswoode, C.N., Pilgrim, J.D., Fishpool, L.D.C. \& Collar, N.J. (2010). Quantitative criteria for species delimitation. Ibis 152(4): 724-746.

\section{Recommended citation}

Boesman, P. (2016). Notes on the vocalizations of Common Chiffchaff (Phylloscopus collybita). HBW Alive Ornithological Note 422. In: Handbook of the Birds of the World Alive. Lynx Edicions, Barcelona. (retrieved from http://www.hbw.com/node/1254361 on 7 December 2016). 